\title{
Improved Conversion Rates in Drug Screening Applications Using Miniaturized Electrochemical Cells with Frit Channels
}

\author{
Mathieu Odijk,* Wouter Olthuis, and A. van den Berg \\ BIOS Lab-on-a-Chip Group, MESA+ Institute for Nanotechnology, University of Twente, Enschede, The Netherlands
}

\author{
Liang Qiao* and Hubert Girault \\ Laboratory of Physical and Analytical Chemistry, EPFL, Lausanne, Switzerland
}

\begin{abstract}
This paper reports a novel design of a miniaturized three-electrode electrochemical cell, the purpose of which is aimed at generating drug metabolites with a high conversion efficiency. The working electrode and the counter electrode are placed in two separate channels to isolate the reaction products generated at both electrodes. The novel design includes connecting channels between these two electrode channels to provide a uniform distribution of the current density over the entire working electrode. In addition, the effect of ohmic drop is decreased. Moreover, two flow resistors are included to ensure an equal flow of analyte through both electrode channels. Total conversion of fast reacting ions is achieved at flow rates up to at least $8 \mu \mathrm{L} / \mathrm{min}$, while the internal chip volume is only $175 \mathrm{~nL}$. Using this electrochemical chip, the metabolism of mitoxantrone is studied by microchip electrospray ionization-mass spectrometry. At an oxidation potential of 700 $\mathrm{mV}$, all known metabolites from direct oxidation are observed. The electrochemical chip performs equally well, compared to a commercially available cell, but at a 30 -fold lower flow of reagents.
\end{abstract}

Tn the past few decades, costs to develop a new drug, 1 accepted by the U.S. Food and Drug Administration (FDA), have grown exponentially, to an estimated 802-1318 million dollars. ${ }^{1}$ FDA approval is important, since the United States is, by far, the largest of all of the international markets. The typical workflow of drug screening starts with years of extensive preclinical research. ${ }^{2}$ In this preclinical research, often large numbers of molecules are tested with the goal of identifying the most promising candidate. These in vitro tests often look at binding to receptors, effects on enzyme activities, toxic effects, or other in vitro parameters. For these in vitro tests, only small amounts of the molecule are required. The next step in preclinical trials involves larger volumes of promising candidates, which are produced for animal model testing. In the end, only one or very few compounds are selected for further clinical trials. These clinical trials are conducted in several phases to establish the safety for use in human subjects. In this paper, we present an approach to use miniaturized electrochemical cells to mimic the metabolism of drugs, aiming to reduce the required amount of time and money involved with the preclinical part of drug screening and to limit the amount of animal testing to the absolute minimum.

One of the major enzyme families that play a role in how drugs are processed in the human body is the cytochrome P450 (CYP450) superfamily. CYP450 enzymes are responsible for the oxidative metabolism of $\sim 75 \%$ of the marketed drugs in current clinical use. ${ }^{3-5}$ Understandably, the study of CYP450 metabolic reactions is one of the important steps in current (preclinical) drug screening methods.

In general, four in vitro methods have been recognized to mimic the in vivo CYP450 drug metabolism reactions. ${ }^{6}$ The method that is easiest to compare to the in vivo situation is the enzymatic model, which uses liver cell extracts. One of the major drawbacks of this method is that metabolic products might adhere to the cell membrane present in the liver cell extracts, making them undetectable. A second model is based on metalloporphyrin-containing systems. ${ }^{7}$ The idea behind this second model is to mimic the reactive center of the haem group present in the CYP450 enzyme, using a similar molecular structure. The third model is based on the electrochemically assisted Fenton reaction. ${ }^{6}$ This method can be regarded as a chemical way of oxidizing organic compounds using hydroxyl radicals. In the simplest approach, a Fenton reagent containing hydrogen peroxide and a ferrous salt is mixed with an organic compound to study the oxidation products. The simplified Fenton reaction is as follows:

$$
\mathrm{Fe}^{2+}+\mathrm{H}_{2} \mathrm{O}_{2} \rightarrow \mathrm{Fe}^{3+}+\mathrm{OH}^{-}+\bullet \mathrm{OH}
$$

A more ingenious online Fenton method is presented by Jurva et al., ${ }^{8}$ where the $\mathrm{Fe}^{3+}$ cation is reduced in an online

Received: July 6, 2012

Accepted: September 28, 2012

Published: September 28, 2012 
electrochemical flow-through cell, such that the Fe ions are recycled.

Perhaps the most obvious method to induce oxidation reactions is to use direct electrochemical oxidation. In Table 1,

Table 1. Reactions Known to be Catalyzed by CYP450, Compared to the Reactions Observed Using Direct Oxidation in Electrochemical Cells

\begin{tabular}{ll}
$\begin{array}{l}\text { Phase } 1 \text { reactions catalyzed by } \\
\text { CYP450,11,16 }\end{array}$ & \multicolumn{1}{c}{$\begin{array}{c}\text { reactions by direct oxidation } \\
\text { benzylic and aromatic } \\
\text { hydroxylation }\end{array}$} \\
hydroxylation & $\begin{array}{c}\text { allylic/aliphatic hydroxylation } \\
\text { No }\end{array}$ \\
N,O,S-dealkylation & $\begin{array}{l}\text { dehydrogenation } \\
\text { de,21 }\end{array}$ \\
dehydrogenation & N,S,P-oxidation \\
N,S,P-oxidation & \\
epoxidation & \\
alcohol and aldehyde oxidation &
\end{tabular}

a comparison is shown of the reactions that are known to occur in CYP450-based oxidation and direct electrochemical oxidation. ${ }^{9-11}$ Most of the reactions observed by CYP450 catalysis are also observed using direct oxidation, except for epoxidation, alcohol, and aldehyde oxidation reactions. The method is shown to be feasible in numerous studies. ${ }^{9,10,12-32}$ A good comparison of all four methods has been discussed in several reviews and papers., ${ }^{9,6,11}$

Direct electrochemical oxidation is not the same as oxidation by CYP450 (as illustrated in Table 1), but it can be used as complementary tool. Direct oxidation offers several advantages over liver cell microsomal incubation. It is a low-cost method, it can be done online in an automated fashion, and, therefore, it is a fast method. Liver cell microsomal incubations are still regarded as the gold standard; however, in some cases, direct electrochemical oxidation is shown to give more information on the generated metabolites. ${ }^{33}$

In a review by Baumann and Karst, an overview is given of the electrochemical cell designs used for the generation of oxidative metabolism products. ${ }^{11}$ Moreover, Prudent and Girault reviewed modifications to electrospray ionization (ESI) interfaces with the purpose to study electrochemical conversions. ${ }^{34}$ The designs presented in these two reviews include flow-through cells with porous working electrodes, ${ }^{14,35}$ thin-layer cells where the analyte is flushed in a thin layer over the working electrode $e^{36-38}$ or cells where the electrospray ionization interface is used as an electrochemical converter. ${ }^{39-41}$ Macroscale flow-through and thin-layer cells can be bought commercially from companies such as Antec Leyden and ESA.

In electrochemistry-ESI-based setups, a potential for electrochemical conversions is applied between two conducting tubes, connected with a piece of nonconducting tube. The tube downstream is usually part of the ESI interface, and therefore connected to the high-voltage power supply of the mass spectrometer. A more-advanced version of this cell has been shown by Xu et al., ${ }^{39}$ which includes a commercial nonaqueous (type MF-2062, BASi) $\mathrm{Ag} / \mathrm{Ag}^{+}$reference electrode and a platinum wire as the working electrode. Fused-silica tubing acts as a spacer between the working electrode and the counter electrode. This counter electrode is composed of a larger tube fitted around the fused-silica tubing and acts simultaneously as a tip for the ESI interface. The benefit of using the ESI tip as an electrochemical converter is that it opens up the possibility to study shorter living compounds. However, generally, the turnover rates are low. Moreover, care needs to be taken to avoid the hazard of electric shock from the high-voltage power supply of the ESI interface. Floating (and electrically wellinsulated) potentiostats might be required if the ESI tip is not connected to the ground potential.

Miniaturized electrochemical cells in a lab-on-chip format can provide specific advantages. Electrochemical reaction rates are often limited by mass transport of ionic species. Because of the small size, a lab-on-chip device might offer specific advantages to achieve a high conversion efficiency of introduced products. Also, volumes are small, giving the possibility to work with small amounts of products. Another advantage is that miniaturized cells, when combined with tools such as ESI-mass spectrometry (MS), can be used to study short-living reactive intermediates. Moreover, lab-on-chip devices can be used as low-cost disposables if produced in sufficient quantities. Disposable devices also circumvent the need for extensive cleaning procedures of the electrodes after use.

Many of the miniaturized cells reported in the literature consist of planar electrodes deposited on a substrate, covered with another substrate containing microfluidic channels, inlets, and outlets. This approach is demonstrated using various substrates, such as glass/PDMS, ${ }^{42,43} \mathrm{PET}^{44}{ }^{44}$ polyimide, ${ }^{45}$ and Polystyrol. $^{46}$ Alignment during the bonding of these two substrates can be difficult, especially if small electrodes are considered.

Several other methods have been published for fabricating miniaturized flow-through cells. Probably one of the easier methods is to use a piece of plexiglass, with drilled microfluidic channels and inserted wires as electrodes. ${ }^{47,48}$ The drawback of this approach is that the size of the microfluidic channels is limited by the size of the drill. Therefore, the internal volumes of those cells is generally quite large (on the scale of several microliters to milliliters).

Another easy fabrication method comprises the use of fluorinated ethylene propylene (FEP, shrink tubing), which is shrunk and simultaneously melted around a channel template (a tungsten wire). ${ }^{49}$ Electrodes are melted into the FEP, either perpendicular or parallel to the tungsten channel template. Afterward, the tungsten wire is removed to open the channel. The major drawback of this method is that it is not easy to predict the area of the electrode that is in contact with the electrolyte.

Liljegren et al. fabricated a flow-through cell specifically designed for conversions in electrochemistry-MS applications. ${ }^{50}$ Their cell is based on thin gold wires, wound around a 50- $\mu$ m-diameter stainless steel wire channel template cast in PDMS. An ESI needle is also integrated into the total chip. Using this cell, subsecond transfer times between the electrochemical cell and the MS signal are reported. However, the major drawback of this cell is the limited conversion efficiency of $30 \%$ at a flow rate of $0.5 \mu \mathrm{L} / \mathrm{min}$ for the oxidation products of dopamine. Moreover, PDMS is not really suitable for MS applications, since PDMS tends to adsorb ions and swell if exposed to organic solvents such as the frequently used acetonitrile. $^{51}$

A miniaturized device for electrochemical conversions worth mentioning is the device shown by Nissila and co-workers. ${ }^{2,53}$ The main operating principle of their device is based on the photocatalytic properties of the $\mathrm{TiO}_{2}$ pillars present on their device. Under the influence of ultraviolet (UV) light, an 
oxidizing potential becomes available to oxidize products present in the electrolyte between the pillars. The device also has an integrated ESI needle. Electrical forces pull on the liquid cone at the ESI tip, generating a spray. Therefore, the ESI needle drives the liquid through the pillars into the MS. This device is used to mimic the oxidative metabolism of Verapamil, which is a known calcium channel blocker used as antiarrhythmic drug. The major drawback of this approach is that the potential and currents used for the oxidation cannot be determined precisely.

In two previous papers, we show that it is feasible to use a miniaturized integrated three-electrode electrochemical cell for drug metabolism studies. ${ }^{33,54}$ One of the major differences that sets our design apart from others is that a separate side channel is used, containing the counter electrode to isolate the products generated at the counter electrode and the working electrode. The design of the chips is aimed at obtaining high conversion rates of introduced compounds. The main disadvantage we encountered was the high ohmic drop, which especially gave problems at higher flow rates as the current increased. In the previous studies, a sample loop was used to collect reaction products, because direct coupling to the MS was not possible, because of flow rate mismatches between the chip and the MS.

In this paper, we present a novel cell design with frit channels to reduce the ohmic drop. We show that by addition of these channels, the performance is increased significantly. Moreover, two fluidic flow resistors are added to the two channels containing the working and counter electrode to establish a well-defined flow ratio without the use of an extra syringe pump. For the first time, we use this new chip design with direct online microchip ESI to study the conversion of mitoxantrone, which is an intercalating antitumor agent.

\section{EXPERIMENTAL SECTION}

Chip Fabrication. The chip designs used in this paper are shown in Figure 1. It consists of two glass substrates, processed by standard photolithography, sputtering, wet-etching, and powder-blasting techniques. Fabrication of this chip is outsourced to Micronit (Micronit Microfluidics BV, The Netherlands). The geometry of channels and electrodes is optimized for high conversion rates of introduced compounds, following the same calculations as those published in a previous paper. ${ }^{54}$ On each chip, a fluidic inlet is visible on the right. A platinum pseudo-reference is placed upstream next to the inlet. Left of the pseudo-reference, the flow splits into two equal parts through two main microfluidic channels. Each channel contains either the platinum working electrode or the counter electrode.

The outlet of the working electrode channel is connected to external equipment like the ESI interface of the MS. In our previous work, we used a second syringe pump in withdrawal mode to control the flow over the counter electrode, but this additional pump was not required using this new design, as explained below. Two different chips were made. One design (B) contains small connecting channels between both main channels, which act as a sort of porous frit to conduct the current from faradaic reactions that are taking place at the electrodes. The other design (A) did not include these frit channels to be able to compare this new design to our previous work, ${ }^{33,54}$ which did not include these frit channels.

In the design with frit channels, the end of each main channel, just before the outlet, is terminated with a microfluidic flow resistor. These two flow resistors are added to make sure that the flow velocity is indeed split into two equal parts,

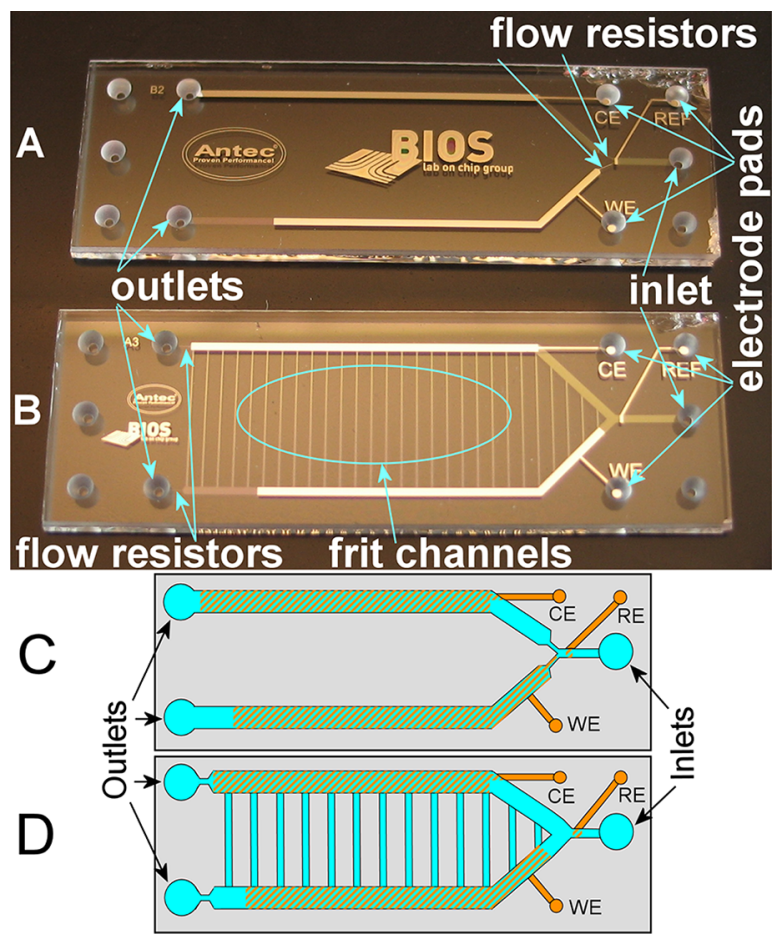

Figure 1. Photograph and schematic drawing of the two designs of the miniaturized three-electrode electrochemical cell without $(\mathrm{A}, \mathrm{C})$ and with $(\mathrm{B}, \mathrm{D})$ frit channels. The main channels have a cross-sectional area of $5 \mu \mathrm{m} \times 500 \mu \mathrm{m}$. The length of the two side channels is $30 \mathrm{~mm}$, whereas the platinum working electrode (WE) and counter (CE) electrode cover the entire width of the bottom of the main channels, with a total length of $24 \mathrm{~mm}$. The platinum pseudo-reference electrode (REF or RE) is placed at the bottom of the inlet channel and has dimensions of $500 \mu \mathrm{m} \times 200 \mu \mathrm{m}$. The perpendicular frit channels have a cross-sectional area of $5 \mu \mathrm{m} \times 100 \mu \mathrm{m}$ and are $9.4 \mathrm{~mm}$ in length.

regardless of small differences in fluidic resistance caused by tubing and additional equipment connected to the outlets of the chip. In the no-frit design, these flow resistors are included directly after the $\mathrm{T}$-junction, where the flow is split to prevent products generated at the working electrode to diffuse back to the pseudo-reference electrode at low flow rates. The working electrode is also present at the bottom of the flow resistor in the no-frit design.

The main channels in both chip designs have a crosssectional area of $5 \mu \mathrm{m} \times 500 \mu \mathrm{m}$. The length of the two side channels is $30 \mathrm{~mm}$, whereas the electrodes cover the entire width of the bottom of the main channels with a total length of $24 \mathrm{~mm}$. The perpendicular frit channels have a cross-sectional area of $5 \mu \mathrm{m} \times 100 \mu \mathrm{m}$ and are $9.4 \mathrm{~mm}$ in length. The length of the frit channels is chosen such that it takes hours for products generated at the counter electrode to diffuse to the working electrode, assuming there is no flow (convection) in the frit channels. The total volume inside the chip is $\sim 175 \mathrm{~nL}$.

Chemicals. Cyclic voltammetry results were obtained using a solution of $1 \mathrm{mM}$ potassium ferrocyanide, $1 \mathrm{mM}$ potassium ferricyanide, and $0.1 \mathrm{M} \mathrm{KNO}_{3}$ as a supporting electrolyte. Chronoamperometric measurements were conducted using a solution of $0.42 \mathrm{mM}$ potassium ferrocyanide, $0.42 \mathrm{mM}$ potassium ferricyanide, and $0.1 \mathrm{M} \mathrm{KNO}_{3}$. Mitoxantrone MS measurements were conducted using a solution of $100 \mu \mathrm{M}$ mitoxantrone, $20 \mathrm{mM} \mathrm{NH} \mathrm{HCO}_{3}$ (>99.5\% Fluka) supporting electrolyte dissolved in 50/50/1 vol \% water/acetonitrile (>99.9\% ABCR $\mathrm{GmbH}) /$ formic acid (>98\% Merck). Sheath 


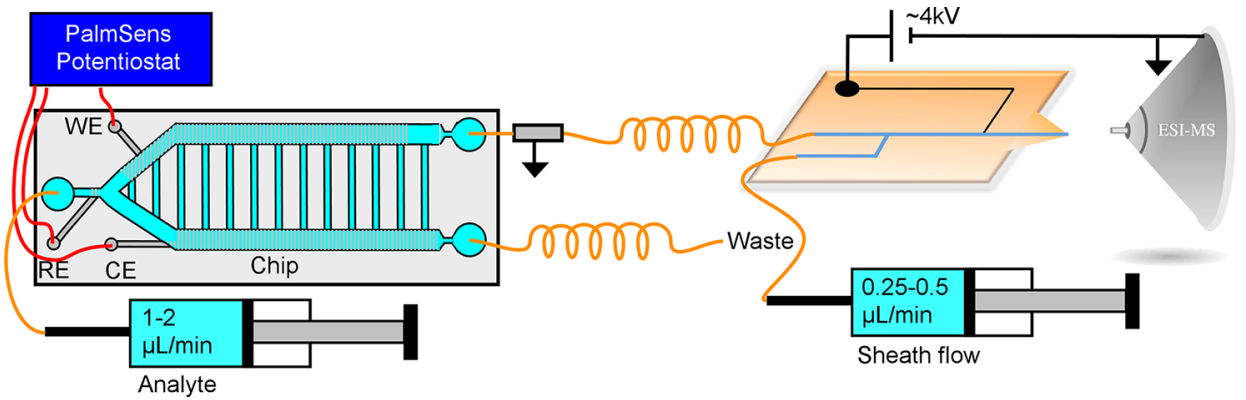

Figure 2. Schematic overview of the setup used for the drug metabolism studies. A syringe pump introduces analyte into the electrochemical chip. Electrode potentials are controlled by a Palmsens potentiostat. The outlet of the working electrode channel is connected to the microchip ESI using a grounded metal union and a 35-cm-long piece of fused-silica tubing with an inner diameter of $75 \mu \mathrm{m}$ to provide sufficient electrical resistance.
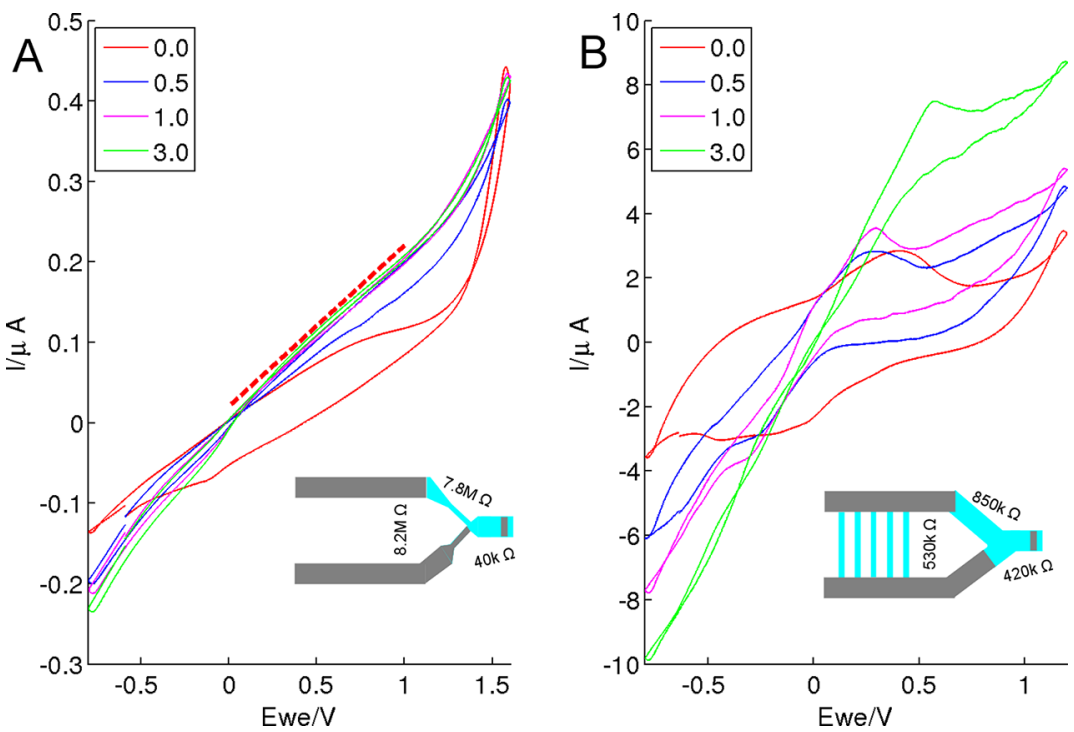

Figure 3. Cyclic voltammetry measurements of the chip design (a) without frit channels and (b) with frit channels in a solution of $1 \mathrm{mM} / 1 \mathrm{mM}$ ferrocyanide/ferricyanide and $0.1 \mathrm{M} \mathrm{KNO}_{3}$ at a scan rate of $40 \mathrm{mV} / \mathrm{s}$ at flow rates of $0 \mu \mathrm{L} / \mathrm{min}$ (red), $0.5 \mu \mathrm{L} / \mathrm{min}$ (blue) $1.0 \mu \mathrm{L} / \mathrm{min}$ (pink), and 3.0 $\mu \mathrm{L} / \mathrm{min}$ (green). The schematic picture of both chip types indicates resistance measurements between the three electrodes. Note the difference in current range between panel (a) and panel (b).

flow was supplied using a buffer solution of 50/50/1 vol \% water/methanol/acetic acid to get a more stable electrospray. All chemicals are obtained from Sigma-Aldrich, unless otherwise mentioned, and high-performance liquid chromatography (HPLC)-grade solvents or deionized water (Milli-Q water purification system) are used to prepare the solutions.

Methods and Setup. In Figure 2, the overall setup is indicated. The electrochemical chip was connected to a syringe pump (Model 210, KD Scientific) using fused-silica tubing and the Fluidic Connect 4515 chipholder from Micronit, which also provides electrical connections by spring metal contact probes. For the cyclic voltammetry and impedance experiments, a Biologic SP-300 potentiostat (Bio-Logic SAS, France) was used. Impedance measurements were conducted by recording a Bode plot between $1 \mathrm{~Hz}$ and $1 \mathrm{MHz}$ using a sine wave of 10 $\mathrm{mV}$ amplitude. Listed impedance values are determined from the resistive plateau at $0^{\circ}$ phase in the Bode plot, to make sure that the impedance from the electrical double layer is not included in the overall value. In MS and UV experiments, a Palmsens (Palm Instruments B.V., The Netherlands) portable potentiostat was used to apply fixed potentials in chronoamperometric mode for $6 \mathrm{~min}$.

For the conversion efficiency study, the working electrode channel outlet of the chip was connected to an optical flow- through cell (type LPC-10MM, Ocean Optics) with an inner volume of $2.4 \mu \mathrm{L}$. Optical absorbance measurements were conducted using a MayaPro spectrometer (Ocean Optics) and a deuterium light source (type DH-2000, Ocean Optics) attenuated (type FVA-UV) to prevent saturation of the spectrometer. Absorbance was determined by comparing the absorbance of ferricyanide at $418 \mathrm{~nm}$ (extinction coefficient = $1000 \mathrm{M}^{-1} \mathrm{~cm}^{-1}$ ) and a reference wavelength of $500 \mathrm{~nm}$ where no absorbance is observed.

For MS measurements, the working electrode channel of the electrochemical chip was connected to an in-house-developed microchip ESI. The details of this chip can be found elsewhere. ${ }^{55}$ In short, it consists of a polyimide and a polyethylene sheet laminated together. The polyimide sheet is processed by laser ablation to provide microfluidic channels and carbon ink is added to provide the electrode required to transfer the high voltage to the liquid inside the ESI tip. The channels of the ESI chip are $50 \mu \mathrm{m} \times 100 \mu \mathrm{M}$ in size. A metal connector with low dead volume was placed between the electrochemical chip and the ESI chip, to provide electrical grounding and decoupling of the two different chips. Because a conductive buffer was used to get a good conversion efficiency in the electrochemical chip, a $35-\mathrm{cm}$-long piece of fused-silica tubing with an inner diameter of $75 \mu \mathrm{m}$ was placed between the 

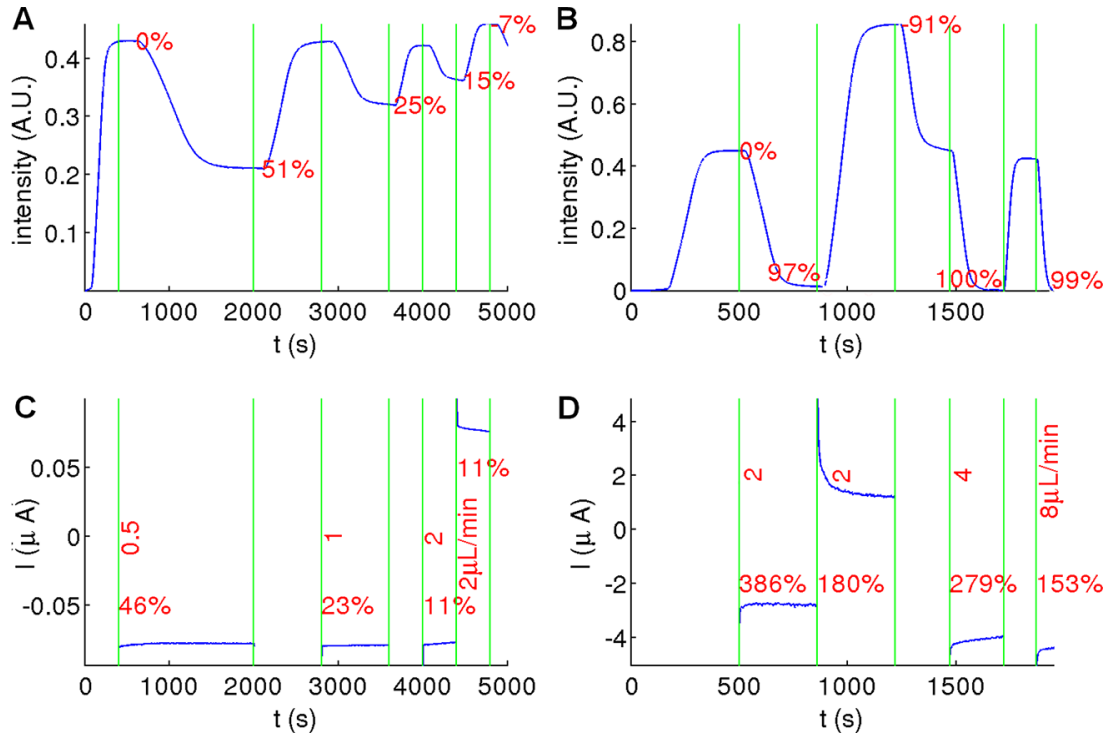

Figure 4. $(c, d)$ Chronoamperometric and $(a, b)$ optical absorbance measurements of the chip design without frit channels (panels (a) and (c)) and with frit channels (panels (b) and (d)) in a solution of $0.42 \mathrm{mM} / 0.42 \mathrm{mM}$ ferrocyanide/ferricyanide and $0.1 \mathrm{M} \mathrm{KNO}_{3}$ at various flow rates.

grounded connector and the ESI chip, to provide sufficient electrical resistance such that no gas bubbles were formed by water electrolysis at the ESI electrode. To ensure that the flow over both the working electrode and the counter electrode channel remained equal, an equally long piece of tubing with same diameter was connected to the counter electrode channel. During the metabolism studies, an LTQ mass spectrometer (Thermo Scientific) was used. A sheath flow of 50/50/1 vol \% water/methanol/acetic acid was infused via the ESI chip under various flow rates to adjust the $\mathrm{pH}$ of sample solution and the surface tension of solvent for good ESI performance.

Safety Considerations. Special care is required to prevent the hazard of electric shock from the high voltage applied to the ESI chip. Be sure to ground the liquid, to isolate the ESI part from the rest of the system, e.g., using a grounded metal connector between the fused-silica tubing.

\section{RESULTS AND DISCUSSION}

Electrochemical Chip Characterization. Figure 3 shows cyclic voltammetry $(\mathrm{CV})$ results measured in $1 \mathrm{mM} / 1 \mathrm{mM}$ ferrocyanide/ferricyanide and $0.1 \mathrm{M} \mathrm{KNO}_{3}$ at various flow rates for both chip designs without frit (Figure 3a) and with frit (Figure $3 b$ ). The CV diagrams of the chips with frit (Figure 3b) correspond to that of a reversible redox couple in the presence of a controlled diffusion layer thickness, as illustrated by the steady-state current after the peak. The microfluidic channel is only $5 \mu \mathrm{m}$ in height, which is depleted within milliseconds. On the seconds time scale, this depletion will not be visible in the diagram. However, at low flow rates, depletion effects are clearly visible in the diagram by the lower current at maximum voltages, compared to the peak current at $\sim 0.15 \mathrm{~V}$. Most of this diffusive behavior is caused by ions diffusing from the frit channels to the electrodes. At higher flow rates, convection becomes the most dominant transport mechanism. This results in higher peak currents and a shape that is similar to the CV diagrams observed using the rotating (ring)-disk electrode technique. Higher flows lead to higher currents, which, combined with the ohmic drop, results in increased peak separation. Ohmic drop is usually referenced in the literature as the uncompensated electrolyte resistance between the working electrode and the reference electrode. ${ }^{56}$

The insets of Figure 3 indicate impedance measurements between the three electrodes of both chip types. In the case of the chip with frit channels, the electrolyte resistance between the working electrode and the reference electrode is $420 \mathrm{k} \Omega$, that between the counter electrode and the reference electrode is $850 \mathrm{k} \Omega$, and that between the working electrode and the counter electrode is $530 \mathrm{k} \Omega$. The frit channels clearly offer a less-resistive path between the working electrode and the counter electrode. As a result, less current is flowing through the channel between the working electrode and the reference electrode, effectively reducing ohmic drop. This chip layout can be simplified to an equivalent electronic network of a resistor of $530 \mathrm{k} \Omega$ in parallel to two resistors of $420 \mathrm{k} \Omega$ and $850 \mathrm{k} \Omega$ in series, connected to a current source. The resulting potential drop over the $420-\mathrm{k} \Omega$ resistor at $8 \mu \mathrm{A}$ is $1 \mathrm{~V}$. The peak separation observed at a flow rate of $3 \mu \mathrm{L} / \mathrm{min}$ is $0.8 \mathrm{~V}$. The ohmic drop, in practice, is smaller, compared to the predicted drop from the electronic network calculations, which we believe is caused by the use of an oversimplified network model.

The curves obtained from the chips without frit (Figure 3a) show mostly ohmic behavior, meaning that there is a clear slope observed in the curves. Also, a small amount of hysteresis is observed, indicating that some faradaic reactions are occurring. Moreover, peak currents are not increasing at flow rates above $0.25 \mu \mathrm{L} / \mathrm{min}$, indicating that not all ferrocyanide is converted inside the working electrode channel. From the fields of electroplating and neuronal stimulation, it is already wellknown that nonuniform current densities lead to hot spots or only parts of the total electrode surface participating in the faradaic reactions. ${ }^{57-59}$ We believe that the slope observed in cyclic voltammetry diagrams of the no-frit chip are caused by a nonuniform current density over the working electrode. In general, a certain overpotential must exist between the ions in the solution and the electrode to drive the faradaic reactions. At increasing potentials, a larger area of the working electrode has sufficient overpotential to convert ions, which is linearly related to the resistance of the electrolyte over the working electrode. In contrast to the explanation of the ohmic drop given for the 
frit chips, the ohmic behavior of the no-frit chip cannot directly be explained by the (AC) impedance measurement between the working electrode and the reference electrode. The actual resistance between these two electrodes is different during conversion, because of the inhomogeneous current density, especially inside the flow resistor of the working electrode channel.

Figure 4 shows current and optical absorbance measurements in time at varied flow, while a constant potential of either $0.5 \mathrm{~V}$ or $-0.5 \mathrm{~V}$ is applied to the no-frit chips (Figures 4a and $4 \mathrm{c}$ ) and frit chips (Figures $4 \mathrm{~b}$ and $4 \mathrm{~d}$ ). Theoretically, the current $(i)$ can be calculated using the following formula:

$$
i=Q C F
$$

where $Q$ is the flow rate over the working electrode (recorded in units of $\mathrm{L} / \mathrm{s}$ ), $C$ the bulk concentration of converted species (given in units of $\mathrm{mol} / \mathrm{L}$ ), and $F$ the Faraday constant (given in units of coulomb $/ \mathrm{mol}$ ). The conversion efficiency can be calculated by dividing the measured current over the theoretical current. For each flow rate, this efficiency is calculated and listed in Figures $4 \mathrm{c}$ and $4 \mathrm{~d}$. The flow rates listed in the figure are the flow rates as delivered by the syringe pump. The flow rate over the working electrode is half of that value. Analyte solution from the outlets is collected and weighted to make sure that this is indeed the case. The efficiencies reported in Figures $4 \mathrm{a}$ and $4 \mathrm{~b}$ are calculated using the following formula:

$$
\text { Eff }=\frac{A_{\text {meas }}-A_{\text {init }}}{A_{\text {init }}}
$$

where $A_{\text {init }}$ is the initial absorbance $(0.42 \mathrm{AU})$ and $A_{\text {meas }}$ the measured value at the point where the value is listed in the figure.

For the frit chips, significantly higher currents are measured than expected for the conversion of ferricyanide to ferrocyanide alone. Apparently, other reactions take place at the electrode as well, effectively increasing the measured current. The reduction of protons to hydrogen is the most likely candidate for the added reduction currents, because the electrolyte does not contain a $\mathrm{pH}$ buffer. At oxidative potentials, it is more difficult to identify an added reaction taking place, besides the oxidation of ferrocyanide to ferricyanide. Based on the applied potential of $0.5 \mathrm{~V}$, we expect that oxidation of water to oxygen gas is not yet taking place. The optical measurements confirm that, in fact, all ferricyanide or ferrocyanide is totally converted up to a flow rate of $8 \mu \mathrm{L} / \mathrm{min}$. The total conversion of ferricyanide is observed at even higher flow rates, up to $16 \mu \mathrm{L} / \mathrm{min}$ in some experiments; however, generally, leakages were observed at some point, because the pressure in the microfluidic system becomes too high above $8 \mu \mathrm{L} / \mathrm{min}$ for reliable operation.

For the no-frit chips, conversion efficiencies reported from the current measurements show good agreement with the conversion efficiencies reported from the optical measurements. Clearly, the limited current due to the high resistance of the microfluidic channels limits the amount of ions that can be converted inside the chip. Approximately 50\% of the ferricyanide is converted at $0.5 \mu \mathrm{L} / \mathrm{min}$. At twice the flow rate $(1 \mu \mathrm{L} / \mathrm{min})$, half of the conversion efficiency $(25 \%)$ is reported. Based on that observation, it can be extrapolated that total conversion of ions is only possible at flow rates below 0.25 $\mu \mathrm{L} / \mathrm{min}$ for the no-frit chip.

Metabolism of Mitoxantrone. Mitoxantrone (MX) is an intercalating antitumor agent that is used in the treatment of leukemia and other cancer types. It is known to have toxic effects and forms reactive intermediates. As already shown in a paper by Lohmann and Karst, ${ }^{21}$ MX $(m / z 445)$ can be oxidized at $300 \mathrm{mV}$, resulting in the formation of a quinone (MXQ $\mathrm{m} / z$ 443 ) and a quinone diimine (MXQQDI, $m / z$ 441). At higher voltages, products at $\mathrm{m} / z 457$ and 473 also are observed, which can be explained by the introduction of one or two $\mathrm{O}$ atoms into the molecule. The reaction mechanism is shown in Scheme 1.

Scheme 1. Oxidative Reaction Mechanism of Mitoxantrone $(\mathrm{MX})$ into a Quinone (MXQ $m / z$ 443) and a Quinone Diimine (MXQQDI, $m / z$ 441)<smiles>O=C1c2c(O)ccc(O)c2C(=O)c2c(NCCNCCO)ccc(NCCNCCO)c21</smiles>
$\mathrm{MX}$

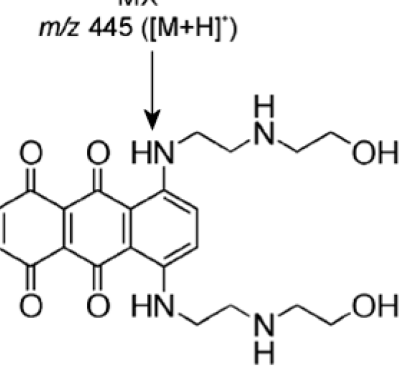
$M \times Q$

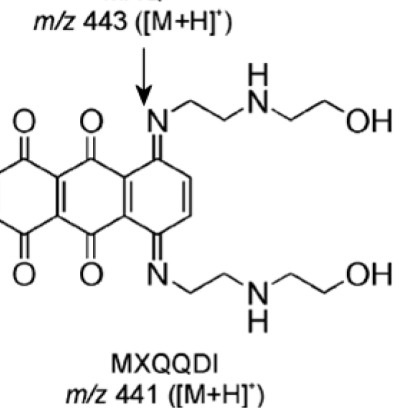

Figure 5 shows mass spectra measured with potentials of $0 \mathrm{~V}$ (Figure 5a), $300 \mathrm{mV}$ (Figure 5b), and $700 \mathrm{mV}$ (Figure 5c) applied to the working electrode at a flow rate of $1.5 \mu \mathrm{L} / \mathrm{min}$ through the chip and an added sheath flow of $0.5 \mu \mathrm{L} / \mathrm{min}$ inside the ESI chip. The employment of sheath flow is important to maintain good ESI performance when a supporting electrolyte is used in the electrochemical chip. At $0 \mathrm{~V}$, a small amount of oxidative products is already observed, which probably results from the ESI interface. A clear increase of the quinone product $(\mathrm{MXQ} m / z 443)$ and a decrease of the starting product $\mathrm{MX}(\mathrm{m} / z 445)$ is observed at $300 \mathrm{mV}$. At 700 $\mathrm{mV}$, the amount of $\mathrm{MX}$ is decreased further, resulting in increased amounts of the quinone and quinone diimine products. Also, the products at $m / z 457$ and 473 are observed at this potential.

Mass traces recorded at $700 \mathrm{mV}$ are shown in Figure 6a and clearly indicate the decrease of the starting product MX and the increase of the reaction products MXQ and MXQQDI during the $6 \mathrm{~min}$ of applied oxidative potential. The dead volume of 

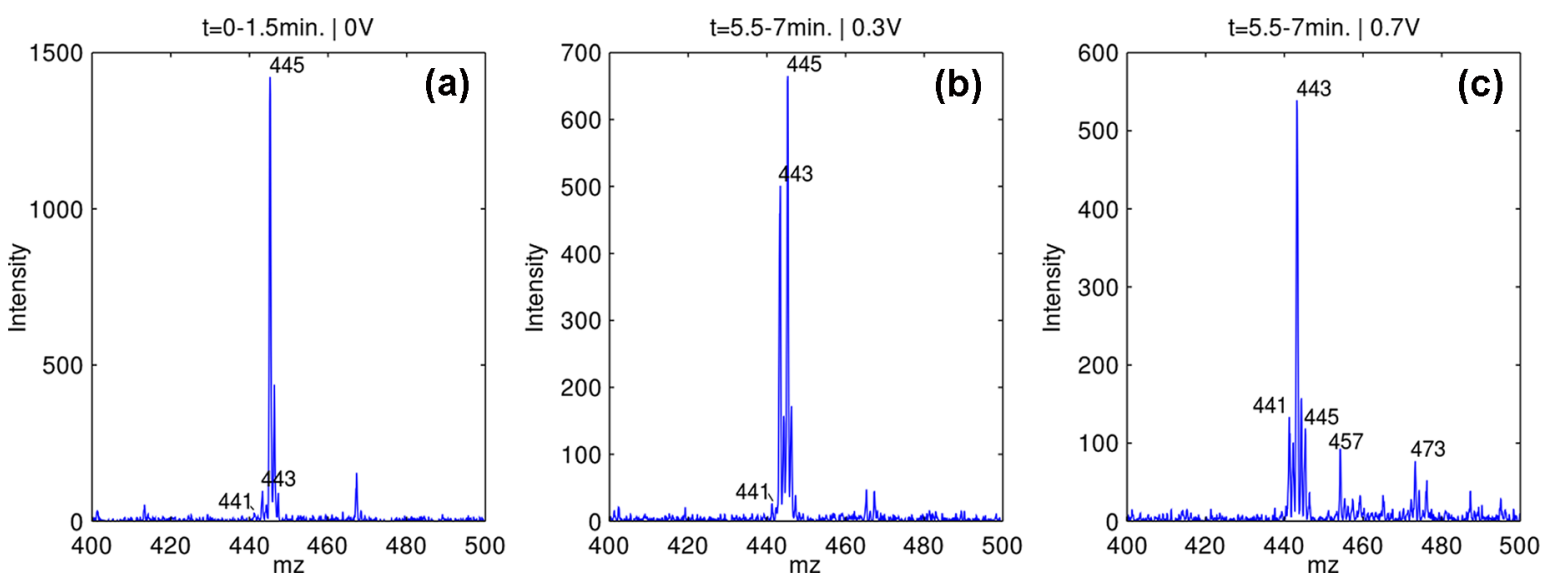

Figure 5. Average mass spectra recorded at working electrode potentials of (a) $0 \mathrm{~V}$, (b) $300 \mathrm{mV}$, and (c) $700 \mathrm{mV}$.
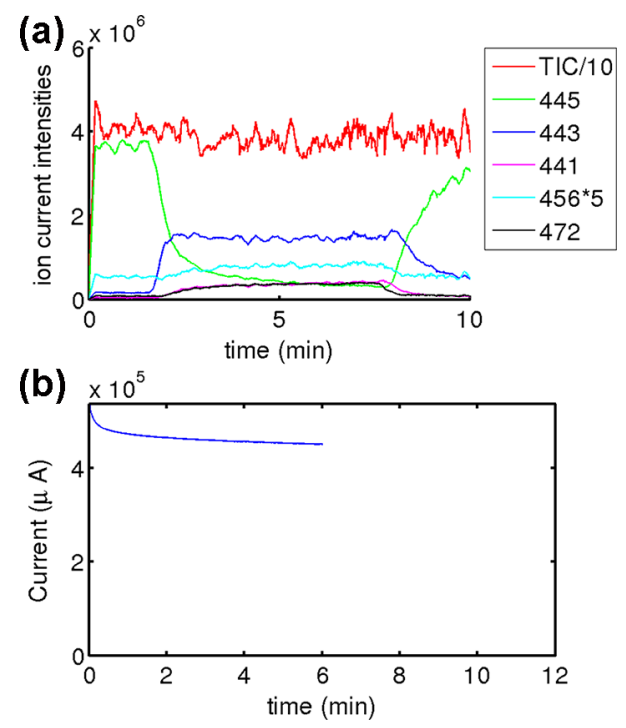

Figure 6. (a) Total ion current (TIC, divided by 10) and mass traces of MX (green), MXQ (blue), MXQQDI (pink), and the reaction products with added oxygen atoms (cyan and black) at an oxidation potential of $700 \mathrm{mV}$. (b) Recorded current from the working electrode.

fluidic connectors and tubing result in a delay of $\sim 1.7 \mathrm{~min}$ at the used flow rate of $1.5 \mu \mathrm{L} / \mathrm{min}$. Figure $6 \mathrm{~b}$ shows the recorded current during oxidation of MX. The current never reaches a stable value, although clear plateaus are visible in the recorded mass traces.

Overall, the shapes of these mass spectra are almost identical to the results published earlier by Lohmann and Karst, ${ }^{21}$ using a model 5020 macroscale-sized guard cell containing a porous glassy carbon working electrode from ESA Biosciences, Inc. (Chelmsford, MA) at a much higher flow rate of $50 \mu \mathrm{L} / \mathrm{min}$. Therefore, it can be concluded that the chip shows similar performance, while using less reagents.

\section{CONCLUSION}

In this paper, a novel chip design is discussed with two new design aspects. Connecting frit channels between the main channels containing either a working electrode or a counter electrode provide a path to conduct current and decrease ohmic drop. Flow restrictors reduce the need for an extra syringe pump to control the flow over each side channel. Overall conversion efficiencies are clearly improved by the frit channels, even at higher flow rates than reported earlier, ${ }^{33,54}$ while maintaining similar internal chip volumes. Moreover, flow resistors are introduced inside each side channel to maintain equal flows.

Cyclic voltammetry (CV) measurements recorded using these new chips show less ohmic drop features, thereby explaining the previously reported $\mathrm{CV}$ diagrams ${ }^{54}$ by a high resistivity between the working electrode and the counter electrode.

Chronoamperometry and optical absorbance measurements at various flow rates show good performance, up to at least 8 $\mu \mathrm{L} / \mathrm{min}$ for the chips with frit channels. The chips without frit channels show only moderate conversion at relatively low flow rates below $2 \mu \mathrm{L} / \mathrm{min}$. Using the improved chip design, the oxidative metabolism of mitoxantrone is studied. The chip is able to generate all known oxidative products. Overall conversion rates in drug oxidation are close to $100 \%$, which is almost identical to results previously reported in the literature $^{21}$ using large scale cells, while the novel chip requires a flow of reagents that is more than a factor 30 lower.

This work opens the way for the design of new chips integrating both the miniaturized electrochemical cell and electrospray in a single chip.

\section{AUTHOR INFORMATION}

\section{Corresponding Author}

*E-mails: m.odijk@utwente.nl (M.O.), liang.qiao@epfl.ch (L.Q.).

\section{Notes}

The authors declare no competing financial interest.

\section{ACKNOWLEDGMENTS}

The authors would like to thank Konstantin Zhurov for his support during the MS measurements. Antec Leyden is acknowledged for financial support in chip fabrication.

\section{REFERENCES}

(1) Munos, B. Nat. Rev. Drug Discovery 2009, 8, 959-968.

(2) FDA, Guidance for Industry, Investigators, and ReviewersExploratory IND Studies. Available via the Internet at http://www.fda. gov/cder/guidance/index.htm, 2006.

(3) Williams, J. A.; Hyland, R.; Jones, B. C.; Smith, D. A.; Hurst, S.; Goosen, T. C.; Peterkin, V.; Koup, J. R.; Ball, S. E. Drug Metab. Dispos. 2004, 32, 1201-1208. 
(4) Wienkers, L. C.; Heath, T. G. Nat. Rev. Drug Discovery 2005, 4, 825-833.

(5) Guengerich, F. P. Chem. Res. Toxicol. 2008, 21, 70-83.

(6) Lohmann, W.; Karst, U. Anal. Bioanal. Chem. 2008, 391, 79-96.

(7) Akagah, B.; Lormier, A. T.; Fournet, A.; Figadere, B. Org. Biomol. Chem. 2008, 6, 4494-4497.

(8) Jurva, U.; Wikström, H. V.; Bruins, A. P. Rapid Commun. Mass Spectrom. 2002, 16, 1934-1940.

(9) Johansson, T.; Weidolf, L.; Jurva, U. Rapid Commun. Mass Spectrom. 2007, 21, 2323-2331.

(10) Baumann, A.; Lohmann, W.; Schubert, B.; Oberacher, H.; Karst, U. J. Chromatogr. A 2009, 1216, 3192-3198.

(11) Baumann, A.; Karst, U. Expert Opin. Drug Metab. Toxicol. 2010, $6,715-731$.

(12) Blankert, B.; Hayen, H.; Kaufmann, J. M. Electroanalysis 2005, 17, 1501-1510.

(13) Gamache, P.; Smith, R.; Acworth, I. Spectroscopy 2003, 18, 1424.

(14) Johansson, T.; Jurva, U.; Gronberg, G.; Weidolf, L.; Masimirembwa, C.; Gro, G. Drug Metab. Dispos. 2009, 37, 571-579.

(15) Jurva, U.; Wikström, H. V.; Bruins, A. P. Rapid Commun. Mass Spectrom. 2000, 14, 529-533.

(16) Jurva, U.; Wikström, H. V.; Weidolf, L.; Bruins, A. P. Rapid Commun. Mass Spectrom. 2003, 17, 800-810.

(17) Jurva, U.; Bissel, P.; Castagnoli, N. J. J. Am. Chem. Soc. 2005, 127, 12368-12377.

(18) Jurva, U.; Holmén, A.; Grönberg, G.; Masimirembwa, C.; Weidolf, L. Chem. Res. Toxicol. 2008, 21, 928-935.

(19) van Leeuwen, S. M.; Blankert, B.; Kauffmann, J.-M. M.; Karst, U. Anal. Bioanal. Chem. 2005, 382, 742-750.

(20) Lohmann, W.; Karst, U. Anal. Bioanal. Chem. 2006, 386, 17011708.

(21) Lohmann, W.; Karst, U. Anal. Chem. 2007, 79, 6831-6839.

(22) Lohmann, W.; Meermann, B.; Karst, U. Anal. Chem. 2008, 80, 9769-9775.

(23) Lohmann, W.; Karst, U. Anal. Bioanal. Chem. 2009, 394, 13411348.

(24) Lohmann, W.; Dötzer, R.; Gütter, G.; Van Leeuwen, S. M.; Karst, U. J. Am. Soc. Mass Spectrom. 2009, 20, 138-145.

(25) Madsen, K. G.; Olsen, J.; Jurva, U. Chem. Res. Toxicol. 2007, 20, $821-831$.

(26) Madsen, K.; Skonberg, C.; Olsen, J. Chem. Res. Toxicol. 2008, 21, 1107-1119.

(27) Madsen, K.; Gronberg, G.; Olsen, J. Chem. Res. Toxicol. 2008, 21, 2035-2041.

(28) Shono, T.; Toda, T.; Oshino, N. Drug Metab. Dispos. 1998, 9, 481-482.

(29) Tahara, K.; Yano, Y.; Kanagawa, K. Chem. Pharm. Bull. 2007, 55, $1207-1212$.

(30) Tahara, K.; Makii, E. Anal. Sci. 2008, 24, 935-938.

(31) Tahara, K.; Nishikawa, T.; Abe, Y. J. Pharm. Biomed. Anal. 2009, 500, $1030-1036$.

(32) Thevis, M.; Lohmann, W.; Schanzer, W. Eur. J. Mass Spectrom. 2008, 14, 163-170.

(33) Odijk, M.; Baumann, A.; Olthuis, W.; van den Berg, A.; Karst, U. Biosens. Bioelectron. 2010, 26, 1521-1527.

(34) Prudent, M.; Girault, H. H. Analyst 2009, 134, 2189-2203.

(35) Diehl, G.; Liesener, A.; Karst, U. Analyst 2001, 126, 288-290.

(36) Deng, H.; Berkel, G. J. V. Electroanalysis 1999, 11, 857-865.

(37) Hambitzer, G.; Heitbaum, J.; Stassen, I. Anal. Chem. 1998, 70, $838-842$.

(38) Regino, M. C. S.; Brajter-Toth, A. Anal. Chem. 1997, 69, 50675072.

(39) Xu, X.; Lu, W.; Cole, R. B. Anal. Chem. 1996, 68, 4244-4253.

(40) Berkel, G. J. V.; Quirke, J. M. E.; Tigani, R. A.; Dilley, A. S.; Covey, T. R. Anal. Chem. 1998, 70, 1544-1554.

(41) Van Berkel, G. J.; Kertesz, V. Anal. Bioanal. Chem. 2012, 403, $335-343$.

(42) Suzuki, H.; Yoneyama, R. Sens. Actuators B 2003, 96, 38-45.
(43) Kim, S. K.; Lim, H.; Chung, T. D.; Kim, H. C. Sens. Actuators B 2006, 115, 212-219.

(44) Rossier, J. S.; Roberts, M. A.; Ferrigno, R.; Girault, H. H. Anal. Chem. 1999, 71, 4294-4299.

(45) Rossier, J. S.; Vollet, C.; Carnal, A.; Lagger, G.; Gobry, V.; Girault, H. H.; Michel, P.; Reymond, F. Lab Chip 2002, 2, 145-150.

(46) Ueno, K.; Kim, H.-B. B.; Kitamura, N. Anal. Chem. 2003, 75, 2086-2091.

(47) Hranček, J.; Červený, V.; Rychlovský, P. Cent. Eur. J. Chem. 2009, 7, 675-682.

(48) Böhm, S.; Pijanowska, D.; Olthuis, W.; Bergveld, P. Biosens. Bioelectron. 2001, 16, 391-397.

(49) Sahlin, E.; ter Halle, A.; Schaefer, K.; Horn, J.; Then, M.; Weber, S. G. Anal. Chem. 2003, 75, 1031-1036.

(50) Liljegren, G.; Dahlin, A.; Zettersten, C.; Bergquista, J.; Nyholm, L. Lab Chip 2005, 5, 1008-1016.

(51) Kim, B.-Y.; Hong, L.-Y.; Chung, Y.-M.; Kim, D.-P.; Lee, C.-S. Adv. Funct. Mater. 2009, 19, 3796-3803.

(52) Nissilä, T.; Sainiemi, L.; Karikko, M.-M.; Kemell, M.; Ritala, M.; Franssila, S.; Kostiainen, R.; Ketola, R. A. In Micro Total Analysis Systems 2009, Proceedings of the uTAS 2009 Symposium; 2009; Vol. 13, pp 1922-1924.

(53) Sainiemi, L.; Nissilä, T.; Jokinen, V.; Sikanen, T.; Kotiaho, T.; Kostiainen, R.; Ketola, R. A.; Franssila, S. Sens. Actuators B 2008, 132, 380-387.

(54) Odijk, M.; Baumann, A.; Lohmann, W.; van den Brink, F. T. G.; Olthuis, W.; Karst, U.; van den Berg, A. Lab Chip 2009, 9, 1687-1693.

(55) Qiao, L.; Lu, Y.; Liu, B.; Girault, H. H. J. Am. Chem. Soc. 2011, 133, 19823-19831.

(56) Bard, A. J.; Faulkner, L. R. In Electrochemical Methods, 2nd ed.; Swain, E., Ed.; Wiley: New York, 2001.

(57) Gobet, J.; Cardot, F.; Bergqvist, J.; Rudolf, F. J. Micromech. Microeng. 1993, 3, 123-130.

(58) Maus, R. G.; McDonald, E. M.; Wightman, R. M. Anal. Chem. 1999, 71, 4944-4950.

(59) Streeter, I.; Compton, R. G. Phys. Chem. Chem. Phys. 2007, 9, $862-870$. 